\title{
Exploring the Social Implications of Patriarchal Influences in Schools
}

\author{
Vahid Shalchi ${ }^{1}$, Roozbeh Hatami ${ }^{2}$, Sirous Tabrizi ${ }^{2}$ \\ Allameh Tabataba'i University ${ }^{1}$, University of Windsor ${ }^{2}$ \\ $\operatorname{Iran}^{1}$, Canada
}

\begin{abstract}
What it means to be masculine can be defined in different ways, though there tends to be popular definitions associated with dominance, aggression, and control. Such popular definitions create problems, particularly when it comes to the social spaces within a school. This is particularly the case for schools that are not engaged in teaching gender equality, or are actively promoting a certain kind of gender discrimination. This paper will explore such issues and discuss the problems inherent in popular definitions and understanding of masculinity. In addition, it will look at the specific situation of Iran, where the schools emphasize gender roles to the point of discrimination in the form of reinforcing patriarchal stereotypes and masculine superiority.
\end{abstract}

\section{Introduction}

In this paper we would like to discuss masculinity in the context of societal expectations, and discuss the effects of some social variables (e.g. family, media, religion, etc.) on such definitions. Some of these variables can result in definitions that may be problematic for promoting gender equality or at least combating gender discrimination. It is not that 'being male' is a problem, but rather the way in which masculinity can be defined and how such definitions are emphasized and socially reinforced that can be problematic. We will then look at some ways in which masculinity can better be understood within the context of the school environment so as to promote social justice. Lastly, we will briefly present some data about Iranian schools, as a simple example of schools that are not engaged in promoting gender equality due to the definition of masculinity used.

\section{Literature review}

What is masculinity? Any discussion on being "masculine" requires an initial discussion on gender. Gender identity refers to one's identification as male, female, or transgender. Many things contribute to the formation of gender identity. Some of these include the environment the individual is raised in (e.g., society, family), and biological factors that are in place before birth [4]. Biological factors that may influence gender identity include pre- and post-natal hormone levels and gene regulation [4]. Social factors include gender messages conveyed by family, mass media, economy, religion, and education [4]. Gender expression refers to the physical manifestation of one's gender identity. This is usually expressed through clothing, mannerisms, and chosen names [23]. In some cases one's gender identity may be inconsistent with their biological sex characteristics, resulting in behaving in a way that is not consistent with cultural gender norms. These gender expressions may be described as gender variant or transgender. Transgender people usually have a gender expression that matches their gender identity rather than their biological sex [23]. However, gender identity is part of a continuous spectrum with man at one end, woman at the other end, and anything between is an androgyny $[4,23]$.

Men and ideas of masculinity are also going through many changes. Men are increasingly required to adjust to the rise of male unemployment and the feminist challenge to patriarchal ideology [22]. For example, the increasing objectification of men's bodies is associated with the emergence of a new consumer culture. With the growth of men's style magazines and male modeling, men are being subjected to 'the look' of both women and men. This is exemplified by the range of new body-sculpting magazines and exercise machines being promoted. It portrays men as a growing social problem because an increasing number of them are uneducated, unemployed, unmarried, or gay all of which are "problems" for masculinity [22]. The view is that school, work, and family are key socializing institutions without which men become unproductive, uncontrollable, and dangerous. For example, the bad behavior of men is seen as responsible for the decline of family values, the growth of single-headed households, and the proliferation of homosexuality [22]. The ideology of masculinism is able to exploit male insecurities and vulnerabilities about sexuality and work, often merely to sell products. It is also used as a basis to perpetuate sexism, thereby reinforcing traditional occupational and reward hierarchies. The myth of male privilege, power, and status blinds men to their own gender oppression and therefore limits the possibilities for an emancipatory transition from within the boundaries of masculinism [22]. The prospects for a balanced future in gender relations then are dependent on the continued unmasking of the 
core ideas that inform masculinism [22].

In the past, many feminists had problems with masculinity in at least two ways. First, masculinity was associated with the institutional practices, attitudes, and personality of men with the practices, attitudes, and personality that promote male dominance and oppress women such as competitiveness, aggression, and control [9]. Thus, masculinity was seen as a social problem inherently opposed to feminist goals. Second, the concept of masculinity was nebulous and inconsistent [9]. However, if masculinity is not the social, cultural, and political expression of maleness, then what is it? Connell writes that, assuming it is even possible to define masculinity, a good definition would be "simultaneously a place in gender relation, the practices through which men and women engage that place in gender, and the effects of these practices in bodily experience, personality and culture" [5, p. 71$]$. Ultimately, it seems that the definition of masculinity has arisen because of the interrelations between gender research and socio / economic pressures to see masculinity in a certain light.

Social variables such as religion, media, family and culture fundamentally affect the development of ideas about masculinity. Furthermore, Freud's commentary on the unconscious - as the part of the mind which gives rise to a collection of mental phenomena that manifest but which the person is not aware of at the time of their occurrence [7] - include phenomena such as unconscious feelings, automatic skills, unnoticed perceptions, unconscious thoughts, unconscious habits and automatic reactions, complexes, hidden phobias and concealed desires all of which can be connected to or reinforce a particular conceptualization of masculinity. A necessary rethinking of masculinity starts acknowledging that the physical sense of maleness and femaleness is linked to the cultural interpretation of gender [5]. The masculine gender is "among other things a certain feel to the skin, certain muscular shapes and tensions, certain possibilities in sex" [5, pgs. 52-53].

There is growing awareness that masculinity is subject to historical, social, and ethnic variations which also enable understanding the oppression of male minorities who do not conform to the current hegemonic definition [27]. Masculinity is not simply about men; definitions of manhood actually provide a standard or norm for men to aspire to rather than describe the status quo of maleness [27]. This distinction is important, given that masculinity is almost always considered directly tied to the physical form of a man's body [5]. Masculine ideology can also arise through gender role socialization, whereby young children internalize cultural norms and expectations about male-appropriate behavior from families, peer groups, and society. Such internalized role norms serve as a means by which men organize and process information about themselves and the external world [14].

The interplay of gender with other structures (e.g., class and race) creates further relationships between definitions of masculinity. Marginalization is always relative to the authorization of the hegemonic masculinity of the dominant group [5]. The challenge to hegemonic definitions of masculinity came from men whose masculinity was cast as deviant: men of color, gay men, and ethnic men. Masculinity therefore cannot be understood as a singular term, but must be examined as masculinities in the plural - the ways in which different men construct different versions of masculinities [19].

It is important to stress that not all models of masculinity are equal, and it crucial to pay careful attention to the function of other factors (e.g., homophobia, sexism) in creating new masculinities. As gender-queer forms continue to emerge, conceptualizations of gay, lesbian, transsexual and, as a result, masculinity and femininity will evolve and produce new conceptual understandings [10]. As a comparative term, masculinity is the opposite of femininity. In its modern convention, the term assumes that one's behavior results from the type of person one is (see, e.g., Table 1).

Table 1. Typical characterization of masculinity [4]

\begin{tabular}{|l|l|}
\hline \multicolumn{1}{|c|}{ Issue } & \multicolumn{1}{c|}{ Characteristics } \\
\hline Bodily strength \& speed & Men are stronger and faster \\
\hline Physical skill & $\begin{array}{l}\text { Men have mechanical skills } \\
\text { Women are good at fiddly work }\end{array}$ \\
\hline Sexual desire & Men have more powerful urges \\
\hline Recreational interest & $\begin{array}{l}\text { Men love sport } \\
\text { Women love gossip }\end{array}$ \\
\hline Character & $\begin{array}{l}\text { Men are aggressive } \\
\text { Women are nurturer }\end{array}$ \\
\hline Intellect & $\begin{array}{l}\text { Men are rational } \\
\text { Women are intuition }\end{array}$ \\
\hline
\end{tabular}

Human beings are incapable of studying human processes without implicating themselves, and the same is true for masculinity researchers [5]. As we explore masculinities, it is important to choose relevant and fruitful areas to study, make appropriate assumptions, and choose language to accurately and adequately describe our knowledge [17].

In the early twenty first century, masculinity in the United States was constructed differently by class culture, race and ethnicity, and age [18]. Since each of these axes of masculinity affected each other, the resulting matrix of masculinities is complicated by cultural issues [18]. Furthermore, if gender varies across cultures, time, and individuals then we really cannot speak of masculinity as a constant, universal essence that is common to all men but rather as an "ever-changing fluid assemblage of meanings and behaviors" [18, p. 124].

Despite such fluidity in meaning, it is still important to consider the practical situation of men in 
the world. For instance: the Columbine high school massacre was committed by men; the murder in 1996 in Queensland Australia was committed by a man; in 1997, the economic activity rate for women is just over two-thirds the rate of men and in Arabic countries it is one-fifth; the world-wide average for women's average income is 56 percent of men's average income; and roughly 93 percent of ministers in the world governments are men [4].

\subsection{Role of family and culture}

The role of "family provider" when seen "as an element of hegemonic masculinity is the material basis of men's authority accepted indicator of their manliness" [16, p. 86]. This is particularly prominent in urban middle class families where the husband is provider and is thus usually not an active presence during the family's waking hours as employment requires total dedication to the company [16]. This concept encourages men to consider their financial contribution as their single most important family responsibility, since failure to provide means a loss of respect and authority in the family and, consequently, a loss of masculinity. Coontz [6] notes that changing demographics and shifting social norms necessitate people to behave in alternative and non-conventional enactments of gender, work, and family if they are to survive the modern-day social and economic pressures of life.

These expectations originate largely from the 1950s family model of "father as breadwinner" and mother as "stay-at-home nurturer of the children". These were the norms by which such families, and the fathers within them, were judged. Yet, by looking at the reality of work and life arrangements of today, instead of on traditional gendered expectations, the statistics show that roughly two million fathers in the United States stay home to take care of their children while the mother is the one working $[8,14]$.

\subsection{Role of media in shaping masculinity}

Racialized notions of masculinity are acted out by/through sexualized tropes: "the 'gangsta' symbolisms, 'do-rags', baggy pants, shirts bearing sports team insignias, and limping walks are designed to invoke a hardened inner-city gangsta style, one portrayed on television and in movies, as a specifically black cultural style" [25, p. 3-4]. Mainstream media representations also play a role in reinforcing ideas about what it means to be a "real" man in our society. In most media portrayals, male characters are rewarded for self-control and the control of others, aggression and violence, financial independence, and physical desirability [25]. Children Now, a California-based organization that examines the impact of media on children and youth, released a report arguing that the media's portrayal of men tends to reinforce men's social dominance: "the majority of male characters in media are heterosexual, male characters are more often associated with the public sphere of work, rather than the private sphere of the home, and issues and problems related to work are more significant than personal issues and that nonwhite male characters are more likely to experience personal problems and are more likely to use physical aggression or violence to solve those problems" [3, p. 1]. The portrayal and acceptance of men by the media as socially powerful and physically violent serve to reinforce assumptions about how men and boys should act in society and how they should treat women, children and each other [3].

The role of masculinity in families and family acceptance depends on media. A problematic stereotype regularly emerges in the media, in the form of commercials, television characters, and parenting magazines that continuously "infantilize men and perpetuate the same incompetence stereotype" $[3, \mathrm{p}$. $2]$, with the mother exemplified as the primary caregiver. As such media perpetuates the stereotypes, more magazines advertisements are sold. More importantly, there is a greater influence on gender politics and subtly perpetuated traditional meanings of masculinity in society.

From a look at the literature on masculinities thus far, it is evident that definitions of masculinity have mostly taken our cultural standpoint for granted but have adopted different patterns and ways to describe and ascribe the masculine concept to a person. Janicki outlines four of these ways which lend from: essentialist, positivist, normative, and semiotic [15].

Essentialism explains that for any specific kind of entity, there is a set of characteristics or properties all of which any entity of that kind must possess. This makes it easy to accurately define concepts and, thus, words or even expressions should have a single definition and meaning, such as the essentialist statement 'all human beings are mortal'. Such definitions "usually pick a feature that defines the core of the masculine, and hang an account of men's lives on that." $[5$, p. 68] The essential approach is weak: "the choice of the essence is quite arbitrary. Nothing obliges different essentialists to agree and in fact they often do not. Claims about a universal basis of masculinity tell us more about the ethos of the claimant than about anything else." [5, p. 69]

Positivism, as a second conceptualization of masculinity, outlines a set of epistemological perspectives and philosophies of science which states that scientific approaches best uncover processes by which both physical and human events occur [20]. Positivist social science stresses the finding of the facts and yields a simplistic definition of masculinity [5]. This definition states what men actually are and is the logical basis of masculinity/femininity (M/F) scales in psychology.

The third approach, normative, create definitions 
that acknowledge differences identified through a positivist approach and propose a standard view; that of masculinity as what men ought to be [5]. This definition is often found in media studies, such as in discussions of "exemplars such as John Wayne or of genres such as the thriller" [5, p. 70]. Although normative definitions allow different approaches to the standards to different degrees, this soon produces paradoxes 'few men actually match the 'blueprint' or display the toughness and independence acted by Wayne, Bogart or Eastwood." [28, p. 32-33]

The semiotic approach argues against the personality perspective and instead suggests defining masculinity "through a system of symbolic differences in which masculine and feminine places are contrasted" [5, p. 70]. Masculinity, in this sense, is not and should not be defined as not-femininity: "in the semiotic opposition of masculinity and femininity, masculinity is the unmarked term, the place of symbolic authority. The phallus is master-signifier and femininity is symbolically defined by lack. This definition of masculinity has been very effective in cultural analysis. It escapes the arbitrariness of essentialism and paradoxes of essentialism and paradoxes of positivist and normative definitions" [28, p. 33].

\section{Masculinity and schools}

There exists hierarchies of masculinities in every setting including school institutions, and each setting will invariably perpetuate its own dominant (hegemonic) masculinity discourse which features prominently over all other forms of masculinity; it becomes "culturally exalted" and personifies what it means to be a "real" boy [5]. So what roles do teachers play in this? Do they reify or disrupt such hegemonic positions of masculinity? How do their actions/inactions affect students, especially boys? The following paragraphs attempt to discuss these issues.

Hidaka [11] found in his study of masculinity discourse in schools that male teachers are often seen by boys as strict disciplinarians who were aloof from students, although some are construed as play-mates who would join the boys in playing 'men's' sports during recess. Female teachers are more comfortable in associating with the image of the mother. This did not go unnoticed by students who disclosed that teachers treated boys and girls differently and the treatment changed as they graduated to higher grades. For instance, most of his study participants claimed that teachers, especially male teachers, had a soft spot for girls in relation to corporal punishment and this carried over to other aspects of teacher-student interactions: "participants remembered the pet phrases spoken by their teachers, including 'be gentle to girls', 'be kind to girls' and 'men should protect women', reflecting the pampering of girls at school. This, however, also implied the exclusion of girls from the future job market and from adult responsibilities and tasks." [15, p. 57]

In the study conducted by Martino and PallottaChiarolli [21], they found that students from small rural towns (which often lack diversity) feel culturally ignored and isolated and need support. In this sense, the racist practices often engaged in by white boys are understood as another means by which they are able to assert their position of power at the top of a social hierarchy of masculinities in the schooling context. However, some of the boys actively challenged the racist practices of others:

Racism is a problem.... like white boys and how they talk about Indigenous boys, "I do not really like them dark boys because they start too much trouble." But it's not really us, we just get aggravated real easy. They say, 'Oh I do not really like dark people'. It's just little things that I hear when I'm walking past. I do not mean to hear it but, if I hear that type of stuff, I chuck my ear in a bit. I think it is because of their culture and the way they are taught at home.... for Indigenous people respect is the biggest thing you could ever have. [21, p. 142]

In a study on Barbados male youths, Downes [1] found in that the construction of hegemonic masculinity was formulated by the "co-optation of the 'lesser' masculinity of a black middle class by the socially dominant white males" [p. 130]. This process was facilitated primarily through the school system. The education system of Barbados: "perpetuated the myth that Mitchinson reforms had created a meritocratic instrument for social justice, mobility and culture 'refinement' like their white, public school-educated counterparts in England, so these black 'boys of the empire' associated socioeconomic and political dominance-whether in the local or wider imperial contexts- with masculinity itself. Consequently, a share in the fruits of hegemonic masculinity necessitated political enfranchisement, and social and economic justice. Nevertheless, the aggressive masculinity exercised by old boys of the elite schools of Barbados in protecting imperial and colonial interests did nothing to redress the social, political and economic inequities which faced black in the empire" [1, p. 130].

\subsection{Need for gender equality in schools}

Although the social variables listed in section 2 can carry over into the school environment, schools are also involved in spreading and reinforcing social norms. Among such norms include definitions and expectations for gender roles. Schools could also explicitly teach such roles, or engage in teaching the concept of equal treatment of men and women. Peterson [13] argues for several reasons why such a 
topic makes sense to teach in schools, three of which are discussed here.

First, a country that experiences increasing immigration will see larger degrees of diversity in its population but also an increase in minority groups. This diversity may result in greater differences in how masculinity, femininity, and gender roles are seen by students in a classroom. Since students may have a cultural background that views these topics differently, schools could become a place to discuss these differences and share the value of gender equality, rather than allow differing views to result in confusion among students or force a particular interpretation onto them [13].

Second, since public educational institutions have a responsibility to explain the current legal expectations and social norms of their country, gender roles (and gender equality, as it becomes a more common norm) are a part of this [13]. Schools also should discuss the historical circumstances from which these norms arose, since that gives opportunity to share and discuss the historical and social circumstances of other cultures without expecting students of minority backgrounds to blindly adopt the majority norms.

Third, the topic of gender equality is becoming an increasing occurrence in modern societies throughout the world [26]. In other words, gender equality is not simply a norm of certain Western cultures, but an increasing global trend. As more countries begin to adopt laws against gender discrimination, and encourage gender equality in government and business, students of schools that do not discuss gender equality are likely to be unprepared for a world that increasingly expects gender equality [13].

\subsection{The case of gender equality in Iran}

Although it is impossible to adequately explore the degree to which gender equality is being taught in schools in an entire country, we will discuss a brief example for schools in Iran. Paivandi [24] has done wide-ranging research on the state of schools in Iran, particularly focusing on the social sciences and humanities in elementary and high-school levels of the public school system.

In the textbooks for such courses, there is a clearly defined difference in the expectations of men and women. The textbooks clearly state that men and women are not equal, and attempt to justify this inequality by appealing to Islamic legal rulings [24]. Men are described as 'the superior sex', and women are described as 'the second sex,' with descriptions for the social and privates lives that people are expected to live based on their sex [24]. For instance, one textbook stated: "Usually, the father works outside the home. He has the duty to provide food, clothing, and other necessities for his wife and children. In some families the mother works outside the home, as well" [a Grade four social studies textbook, cited in 24].

It is not just the descriptions, but also the way in which images are used to reinforce these ideas. For instance, Paivandi [24] analyzed over 3000 images in textbooks and determined that: women were only present in $37 \%$ of these photos (primarily in group photos), women were absent in photos of workplaces or public areas, men and women were only shown together in $18 \%$ of group photos, and photos of women alone were always in the home. There were also few photos of men in the home, and female historical figures were not even present in the textbooks [24].

This brief example is problematic for the explicit gender discrimination is that involved. While it is not a problem for men and women to have different interests, the textbook material reviewed above indicates that it is the sex of a person that determines what they are allowed to do in society and at home. As will be discussed next, this attitude poses unnecessary limitations on individuals but also creates problems, for men especially, when individuals are unable to live up to the social roles, such as due to economic circumstances or individual interests.

\section{The other international revolution}

The Industrial Revolution was a period from the 18th to the 19th century, started in England around 1733 with the first cotton mill [12]. The Industrial Revolution was the underlying reason for changes in agriculture, manufacturing, mining, transport, and technology. It also had a profound effect on the socioeconomic, cultural conditions starting in the United Kingdom and subsequently spreading throughout Europe, North America, and eventually the entire world. The Industrial Revolution marks a major turning point in human history; almost every aspect of daily life was eventually influenced in some way. Most notably, average income and population began to exhibit unprecedented sustained growth. In the two centuries following 1800, the world's average per capita income increased over 10-fold, while the world's population increased over 6-fold [12]. Factory owners needed cheap and unskilled labor, and they profited greatly by using children and women to run the machines. The movements of the labor changed the situation in the 19th century, such that demand for educated force was increased through increasing population and increasing request for products [12].

One of the main problems for men in contemporary society is that they are no longer initiated into masculinity and masculine value by other men [2]. In contemporary society, the connection between older and younger men has been broken and the economic changes brought by the industrial revolution have almost dissolved the more traditional relationships between boys and their fathers [2]. Prior to the Industrial Revolution, fathers and sons shared close 
cohabitations and fathers passed on trade skills to their sons. Modern production systems have also destroyed the father's ability to pass on masculine values to the son, since the modern father does not work with his sons and, by the time he gets home from work, sees his sons for a few minutes each day [2]. The notion of a 'deep masculinity' [2] is therefore very firmly connected to traditional forms of manhood and fatherhood.

\section{Conclusion}

We now offer some conclusions in keeping with the points raised in this assignment. Some common conceptions of masculinity were presented. For instance, the man is the financial provider; but this means if his wife earns more than him then he has somehow failed in the performance of masculinity. Therefore, a high-earning female (or any female who desires a career) is "emasculating." A second example was that men are interested in sex at all times, and spend their time thinking about sex; regardless of whether this is true, it affects how men perceive themselves and their relationship to women. A third example is that a man is in control of his own life. In my experience this is rarely true of anyone - even leaving all of society behind to live like a hermit only gives some form of control, as there will still be many things beyond your control. The idea that men must be in control encourages men to try to control others in their lives. Fourth, violence is the natural male response to a perceived threat. Again, if this is how a man thinks he should respond then is it any wonder that a man, when faced with a situation where a woman has more control than him, seeks to abuse the woman? And lastly, men are incompetent at housework and should not enjoy it or do it willingly. This suggests to a man that, if he is doing housework or childcare or something, it has to be because a woman pressured him into it, which then causes his opinion of the woman to be "a nagging bitch." All such conceptualizations lead to serious problems in society, which have been well documented throughout the news.

Furthermore, the media plays a fundamental role in defining masculinity for young people and in propagating such images. In popular media, the more common expressions of masculinity include:

- The majority of male characters in media are heterosexual

- Males are more often associated with the public sphere of work, rather than the private sphere of the home, and issues and problems related to work are more significant than personal issues

- Non-white male characters are more likely to experience personal problems and are more likely to use physical aggression or violence to solve those problems

One final point remains: what is it that teachers are doing about these definitions of masculinity? Are teachers merely propagating the same definitions as the media, whether intentionally or not? Are they getting students to critique, discuss, and think about these definitions? Or are they encouraging their own definition of what it means to be masculine? Teachers need to be aware of these issues so that they are not unconsciously propagating undesirable definitions of masculinity.

\section{References}

[1] A.D. Downes, "Boys of the Empire: Elite education and the construction of hegemonic masculinity in Barbados, 1875-1920," Interrogating Caribbean masculinities: Theoretical and empirical analysis, R. Reddock, the University of the West Indies Press, Kingston, Jamaica, 2004.

[2] Ashe, F., The new politics of masculinity: Men, power and resistance, Routledge, New York, NY, 2007.

[3] Children Now, Boys to men: Entertainment media messages about masculinity, Oakland, CA, 1999.

[4] Connell, R.W., Gender, Blackwell Publishing Ltd., Malden, MA, 2002.

[5] Connell, R.W., Masculinities, University of California Press, Oakland, CA, 2005.

[6] Coontz, S., The way we never were: American families and the nostalgia trap (Revised Ed.), Basic Books, New York, NY, 2016.

[7] Freud, S., Civilization and its Discontents, W.W. Norton, 1961.

[9] Gardiner, J., "Introduction," Masculinity Studies and Feminist Theory, 2002.

[8] Gill, L., Stay-at-home dads: The essential guide to creating the new family, Plume Books, New York, NY, 2001.

[10] Halberstam, J., Female Masculinity, Duke University press, Durham, NC, 1998.

[11] Hidaka, T., Salaryman Masculinity. Continuity and change in Hegemonic Masculinity in Japan, Brill Academic Publishers, Boston, MA, 2010.

[12] Hudson, P., The Industrial Revolution, Bloomsbury Academic, New York, NY, 2004.

[13] J. Peterson, "5 Reasons to Teach Gender Equality in Schools," Huffington Post, 2015. Retrieved from http://www.huffingtonpost.com/joel-1-a-peterson/post_10 328_b_8307744.html. (Access date: 2 March 2016).

[14] J.T., Spence, "Gender-related traits and gender ideology: Evidence for a multifactorial theory," Journal of Personality and Social Psychology, Vol. 64, No. 4, 1993, pg. 624-635. 
[15] Janicki, K., "The ever-stifling essentialism: Language and conflict in Poland (1991-1993)," H. Cuyckens, T. Berg, R Dirven, and K. Panther (Eds.), Motivation in language: Studies in honor of Günter Radden, John Benjamins Publishing Company, Philadelphia, PA, 2003.

[16] Kendall, L., Under Construction, University of Hawai'i press, Honolulu, HI, 2002.

[17] Khan, J.S., An Introduction to masculinities, WileyBlackwell Publishing, Malden, MA, 2009.

[18] Kimmel, M.S., and A.B. Aronson, Men and Masculinities, ABC-CLIO, 2004.

[19] Kimmel, M.S., J.S. Hearn, and R.W. Connell, Handbook of studies on Men \& Masculinities, Sage Publication, New York, NY, 2005.

[20] L. Cohen, and A. Maldonado, "Research Methods in Education," British Journal of Educational Studies, Vol. 55, No. 9, Routledge, New York, NY, 2007.

[21] Martino, W., and M. Pallotta-Chiarolli, So What's A Boy?, Open University Press, Philadelphia, PA, 2003.

[22] Money, J., and A.A. Ehrhardt, Man and woman, boy and girl, Jason Aronson, Northvale, NJ, 1996.

[23] Morrow, D.F., and L. Messinger, Sexual orientation and gender expression in social work practice, Columbia University Press, New York Chichester, West Sussex, 2006.

[24] Paivandi, S. (2008). Discrimination and Intolerance in Iran's Textbooks. Washington: Freedom House.

[25] Pascoe, C.J., Masculinity and sexuality in high school, University of California Press, Oakland, CA, 2007.

[26] R. Hausmann, L.D. Tyson, Y. Bekhouche, S. Zaahidi, "The Global Gender Gap Index 2014," Global Gender Gap Report, World Economic Forum, 2014. Retrieved from http://reports.weforum.org/global-gender-gap-report-2014/ part-1/the-case-for-gender-equality/. (Access date: 5 May 2016).

[27] West, R., and F. Lay, Subverting Masculinity, Rodopi, Amsterdam, The Netherlands, 2000.

[28] Whitehead, S.M., and F.J. Barrett, The Masculinities Reader, Blackwell Publishers Ltd, Maldon, MA, 2001. 